\title{
ANALISIS KINERJA KARYAWAN TERHADAP PROMOSI JABATAN PADA PT. SELAMAT LESTARI MANDIRI KOTA SUKABUMI
}

\author{
Neneng Fitri Riani ${ }^{1}$ \\ Faizal Mulia $\mathbf{Z}^{2}$ \\ Erry Sunarya ${ }^{3}$
}

Fakultas Ilmu Administrasi dan Humaniora Universitas Muhammadiyah Sukabumi, Jawa Barat, Indonesia ${ }^{1,2,3}$

Email: nenengfitririani001@ummi.ac.id'1, faizal_88@ummi.ac.id ${ }^{2}$, errysoen@ummi.ac.id ${ }^{3}$

\begin{abstract}
This study aims to find out and understand how much the analysis of employee performance toward the promotion of PT. Selamat Lestari Mndisi Sukabumi. This research uses a quantitative approach where data source are used a tool to obtain data. Sampel used by researchers as many as 75 empoyees the methods used by researchers are descriptive with associative approach. The result of the regression equation formed is $Y=3.061+1.043 X$. The result of the t test study on employee performance variables are $0.000<0,05$ so that $t$ count is 15,491. Each variable has a positive and sifnificant effect on analisis of employee toward job promotion.
\end{abstract}

Keywords : employee performance; job promotion.

\begin{abstract}
ABSTRAK
Penelitian ini bertujuan untuk mengetahui dan memahami seberapa besar analisis kinerja karyawan terhadap promosi jabatan PT. Selamat Lestari Mandiri Sukabumi. Penelitian ini menggunakan pendekatan kuantitatif dimana sumber data yang digunakan dengan cara wawancara dan menyebar kuesioner sebagai alat untuk memperoleh data. Sampel yang digunakan peneliti sebanyak 75 pegawai. Metode yang digunakan peneliti adalah deskriftif dengan pendekatan asosiatif. Hasil persamaan regresi linier sederhana yang terbentuk adalah $\mathrm{Y}=3.061+1.043 \mathrm{X}$. Hasil penelitian uji t pada variabel kinerja karyawan $0.000<0,05$ sehingga t hitung sebesar 15,491. Masing-masing variabel memiliki pengaruh yang positif dan signifikan pada analisis kinerja karyawan terhadap promosi jabatan.
\end{abstract}

Kata kunci : Kinerja Karyawan; Promosi Jabatan. 


\section{PENDAHULUAN}

Seiring dengan berkembangnya zaman setiap organisasi dihadapkan oleh kondisi yang rumit yang menuntut organisasi tersebut memberdayakan semua komponen sumber daya manusia yang dimilikinya. Pengembanagn sumber daya manusia merupakan cara perusahaan agar dapat mempertahankan eksistensi kerja semua kompenen perusahan. Promosi jabatan salah satu cara untuk memberdayakan sumber daya manusia agar terpakai secara efisien, faktor manusia diakui sebagai faktor yang pokok dalam setiap organisasi (Ritonga \& Lubis, 2015).

Promosi jabatan pada perusahaan untuk memotivasi karyawan agar meningkatkan prestasi kerjanya sedangkan karyawan yang mendapatkan promosi jabatan harus memenuhi kriteria yang ditentukan oleh perusahaan. Promosi jabatan salah satu harapan adanya penilaian kinerja yang baik bagi seorang karyawan selain naiknya kompensasi yang bisa karyawan terima dari perusahaan. Promosi jabatan merupakan suatu proses naiknya jabatan atau posisi seseorang, salah satunya dengan adanya kinerja yang baik dari karyawan tersebut. Promosi jabatan merupakan sarana yang dapat mendorong karyawan untuk lebih baik atau lebih bersemagat dalam melakukan suatu pekerjaan dalam suatu lingkungan perusahaan (Suryalena, 2017).

Melalui penilaian kinerja akan diketahui seberapa baik karyawan yang telah melaksanakan tugas yang diberikan oleh perusahaan, penilaian kinerja pada perusahaan untuk mengetahui kekurangan dan potensi seorang karyawan dalam mengerjakan tugas yang diberikan kepadanya. Kinerja merupakan suatu hasil kerja 
yang dicapai seseorang dalam melaksanakan tugas-tugas yang dibebankan kepada yang di dasakan atas kecakapan, pengalaman dan kesungguhan serta waktu (Wibowati, 2014). Dari hasil tersebut organisasi dapat mengembangkan suatu perencanaan sumber daya manusia secara menyeluruh dalam menghadapi masa depan perusahaan. Kinerja karayawan merupakan kemampuan dalam menjalankan tugas dan pencapian standar keberhasilan yang telah ditetapkan oleh perusahaan kepada karyawan sesuai dengan pekerjaan yang telah diberikan pada masingmasing karyawan.

Melihat pentingnya kinerja karyawan maka peneliti tertarik untuk melakukan penelitian pada PT. Selamat Lestarai Mandiri Sukabumi bahwa terkait pada promosi jabatan, karena peniliain kinerja karyawan pada perusahaan dapat mengetahui seberapa kemampuan karyawan dalam mengerjakan tugas dan tanggung jawabnya. Sehingga kualitas kerja karyawan pada perusahaan sangat rendah maka dari itu kriteria pada promosi jabatan akan sulit di dapatkan.

Dalam suatu perusahaan kinerja yang baik akan selalu mencerminkan rasa tanggung jawab yang besar dalam setiap tugas-tugas yang diberikan oleh perusahaan. Kinerja ialah hasil atau tingkat keberhasilan seseorang secara keseluruhan selama periode tertentu di dalam melaksanakan tugas dibandingkan dengan berbagai kemungkinan seperti hasil kerja, target atau sasaran,kriteria yang telah ditentukan terlebih dahulu dan telah ditentukan terlebih dahulu dan telah disepakati sebelumnya (Kridharta \& Rusdianti, 2017). Sedangkan kinerja merupakan hasil kerja secara kualitas dan kuantitas yang dicapai oleh seorang karyawan dalam melaksanakan tugasnya sesuai dengan tanggung jawab yang 
diberikan kepadanya (Triasmoko et al., 2014). Adapun indikator untuk menilai kinerja yang di jelaskan oleh (Sutrisno, 2010) antara lain : (1) Kualitas, (2) Kuantitas, (3) Waktu kerja, dan (4) Kerjasama.

Maka indikator yang digunakan pada penelitian ini yaitu : (1). Kualitas yang dihasilkan menerangkan tentang jumlah kesalahan, waktu, dan letepatan (Basriani \& Martina, 2017) (2). Kuantitas yang dihasilkan berkenaan dengan berapa jumlah produk atau jasa yang dapat dihasilkan (Basriani \& Martina, 2017) (3). Waktu kerja menerangkan akan berapa jumlah absen, keterlambatan, serta masa kerja yang telah dijalani individu pegawai tersebut (Basriani \& Martina, 2017) (4). Kerja sama menerangkan akan bagaimana individu membantu atau menghambat usaha dari teman sekerjanya (Basriani \& Martina, 2017).

Promosi adalah seorang pegawai dipindahkan dari suatu pekerjaan lain yang tanggung jawabnya lebih besar, tingkatannya dalam hirarki jabatan lebih tinggi dan penghasilannya pun lebih besar (Ritonga \& Lubis, 2015). Promosi jabatan dapat mensuplai tenaga kerja internal lebih terjamin, dengan demikian organisasi tidah selalu harus mencari tenaga kerja dari luar organisasi untuk mengisi lowongan yang terjadi secara lateral karena berbagai hal seperti adanya pekerja yang berhenti, diberhentikan, memasuki usia pensiun atau meninggal dunia (Saputra \& Sudharma, 2017). Selanjutnya promosi ialah perpindahan seseorang kesebuah posisi pada level yang lebih tinggi dalam organisasi (Basriani \& Martina, 2017), sedangkan promosi ialah salah satu dari beberapa jenis pengembangan karier, mendapatkan promisi adalah impian atau tujuan seorang karyawan yang memiliki prestasi kerja yang baik (Puspasari \& Satrya, 2019). 
Menurut (Hasibuan, 2013:108) bahwa dimensi promosi jabatan antara lain : Kejujuran, disiplin, prestasi kerja, kerjasama, kecakapan, loyalitas, kepemimpinan, dan pendidikan. Dimensi yang digunakan peneliti senada dengan (Fitri, 2014). Seperti penelitian terdahulu yang telah digunakan maka adanya pengaruh positif dan signifikan antara kinerja karyawan terhadap promosi jabatan (Munadiah, 2015) (Fitri, 2014)

H1 : kinerja karyawan berpengaruh positif dan signifikan terhadap promosi jabatan.

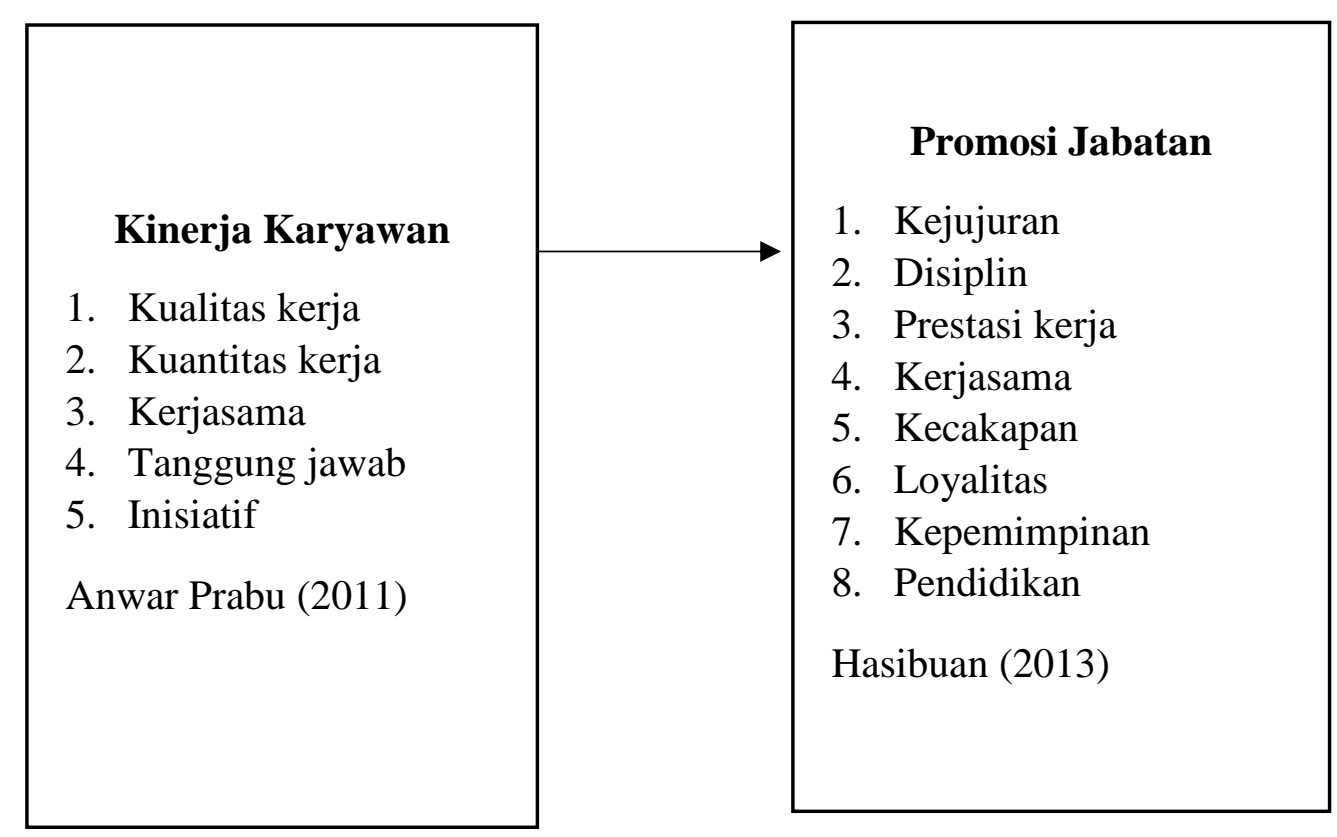

Sumber : Diolah Peneliti, 2020

\section{Gambar 1.}

Model Penelitian

\section{METODE PENELITIAN}

Metode yang digunakan penelitian yaitu metode deskriftif dan asosiatif dimana tujuan dari penelitian ini untuk mengetahui hubungan atara dua variabel 
atau lebih, dalam penelitian ini dilakukan melalui pendekatan kuantitatif dengan menggunakan metode statistik.(Rahayu, 2017)

Populasi ialah kelompok atau kumpulan subjek atau objek yang akan digeneralisasikan dari hasil penelitian (Sunaryo, 2016). Populasi pada penelitian ini adalah pegawai PT. Selamat Lestari Mandiri Sukabumi, dalam penelitian ini jumlah sampel yang digunakan oleh peneliti yaitu sebanyak 75 pegawai pada PT. Selamat Lestari Mandiri Sukabumi. Teknik analisis data yang dilakukan oleh peneliti menggunakan regresi linier sederhana dan pengujian hipotesis menggunakan uji T (Parsial).

\section{HASIL DAN PEMBAHASAN}

Tabel 1.

Hasil Regresi Linier Sederhana

\section{Coefficients $^{\mathrm{a}}$}

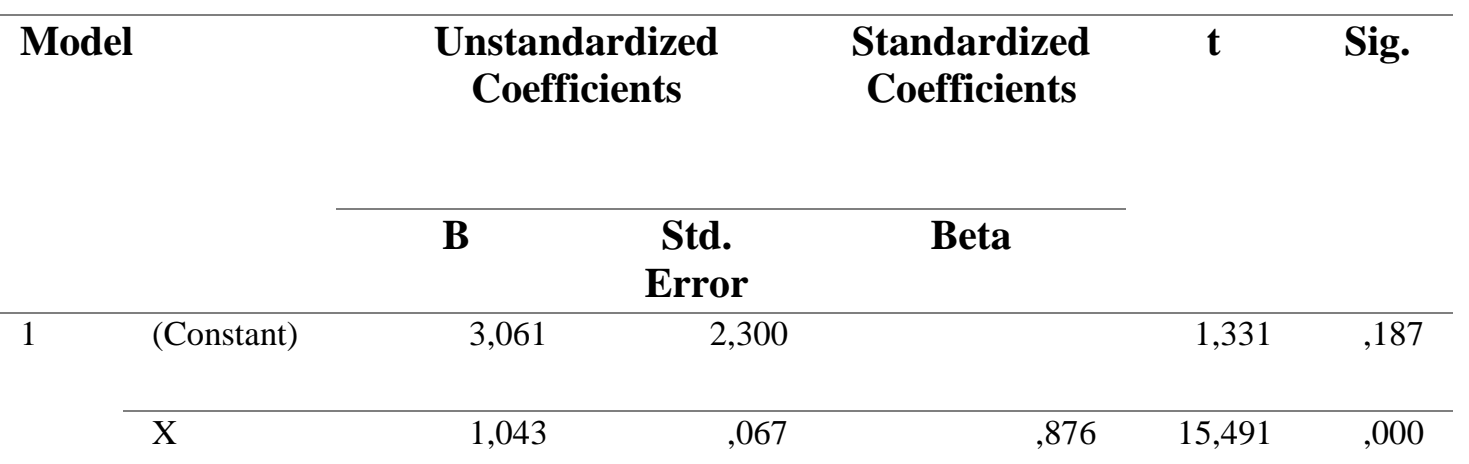

Sumber : Diolah dari SPSS, 2020

Berdasarkan hasil tabel diatas maka apat dibuat model persamaan regresi linier sederhana untuk penelitian ini sebagai berikut :

$\mathrm{Y}=\mathrm{a}+\mathrm{bx}$ 
$\mathrm{Y}=3.061+1.043 \mathrm{X}$

Dari persamaan regresi linier sederhana dapat disimpulkan antara lain : 1). Nilai konstanta 3.061 menunjukkan bahwa nilai koefisien variabel kinerja karyawan yaitu sebesar 3.061. 2). Kemudian nilai koefisien regresi (Y) sebesar 1.043 artinya setiap penambahan $1 \%$ nilai kinerja karayawan maka nilai promosi jabatan akan meningkat sebesar 1.043, sehingga nilai koefisien regresi menunjukkan nilai positif dan dapat dikatakan bahwa pegaruh variabel (X) terhadap (Y) adalah positif.

Tabel 2.

Koefisien Determinasi

\section{Model Summary}

\begin{tabular}{ccccc}
\hline Model & R & R Square & $\begin{array}{c}\text { Adjusted R } \\
\text { Square }\end{array}$ & $\begin{array}{c}\text { Std. Error of } \\
\text { the Estimate }\end{array}$ \\
\hline 1 &, $876^{\mathrm{a}}$ &, 767 &, 764 & 2,94043 \\
\hline
\end{tabular}

Sumber : Diolah dari SPSS, 2020

Pada Tabel 2 menunjukan bahwa nilai koefisien determinasi adalah 0.876 , maka nilai koefisien determinasi sebesar 0.767 sehingga kinerja karyawan terhadap promosi jabatan sebesar 76.7\%. Maka terdapat pengaruh variabel independent yaitu kinerja karyawan terhadap variabel dependent yaitu $76 \%$ sedangkan sisanya $24 \%$ dan adanya pengaruh dari variabel lainnya. Berdasarkan hasil diatas dapat disimpulkan adanya pengaruh positif dan signifikan pada kinerja karyawan terhadap promosi jabatan, hal ini senada dengan (Fitri, 2014) 
Tabel 3.

Uji T (Parsial)

\begin{tabular}{|c|c|c|c|c|c|c|}
\hline \multicolumn{7}{|c|}{ Coefficients ${ }^{\mathrm{a}}$} \\
\hline \multirow{2}{*}{\multicolumn{2}{|c|}{ Model }} & \multicolumn{2}{|c|}{$\begin{array}{l}\text { Unstandardized } \\
\text { Coefficients }\end{array}$} & $\begin{array}{l}\text { Standardized } \\
\text { Coefficients }\end{array}$ & \multirow[t]{2}{*}{$\mathrm{T}$} & \multirow[t]{2}{*}{ Sig. } \\
\hline & & B & Std. Error & Beta & & \\
\hline \multirow[t]{2}{*}{1} & (Constant) & 3,061 & 2,300 & & 1,331 & , 187 \\
\hline & $\begin{array}{l}\text { Kinerja } \\
\text { karyawan }\end{array}$ & 1,043 & ,067 & 876 & 15,491 & , 000 \\
\hline
\end{tabular}

Diolah : dari SPSS, 2020

Berdasarkan hasil pada Tabel 3 dapat dilihat bahwa nilai t hitung variabel kinerja karyawan sebesar 15,491 dengan Sig, 0.000. Nilai Sig, $0.000<0,05$ dan nilai koefisien regresi mempunyai nilai positif sebesar 15,491. Maka H1 diterima artinya ada pengaruh kinerja karyawan secara simultan terhadap promosi. Penelitian ini senada dengan penelitian yang dilakukan (Wibowati, 2014) (Kridharta \& Rusdianti, 2017) (Fitri, 2014). Dapat disimpulkan bahwa kinerja karyawan berpengaruh positif terhadap promosi jabatan.

\section{SIMPULAN DAN SARAN}

Kesimpulan yang diambil dari hasil penelitian mengenai analisis kinerja karyawan terhadap promosi jabatan pada PT. Selamat Lestari Mandiri Sukabumi. Dalam penelitian ini menggunakan teknik analisis regresi linier sederhana untuk menujukan adanay pengaruh variabek kinerja karyawan $(\mathrm{X})$ terhadap promosi jabatan (Y) sehingga hasil uji hipotesis memiliki hubungan positif dan signifikan terdapat variabel $\mathrm{X}$ terhadap $\mathrm{Y}$. 
Berdasarkan hasil penelitian yang diperoleh dari analisis diatas, maka saran yang dapat diberikan oleh peneliti kepada PT. Selamat Lestari Mandiri Sukabumi adalah : (1) Disarankan kepada perusahaan untuk meningkatkan promosi jabatan yang berkualitas agar kinerja karyawan dalam melaksanakan pekerjaan hasilnya akan lebih memuaskan. (2) Pimpinan sebaiknya memberikan arahan dan pelatihan untuk meningkatkan kemapuan karyawan. (3) Kinerja yang dilakukan karyawan sebaiknya lebih diperhatikan lagi untuk menginsentifkan pekerjaan mereka masingmasing karyawan agar pekerjaan yang dilakukan menghasilkan kualitas yang baik.

\section{REFERENSI}

Basriani, A., \& Martina. (2017). Pengaruh Promosi Jabatan Terhadap Kinerja Karyawan Pada PT Tasma Puja Di Pekanbaru. Menara Ilmu, XI(76), 15-28.

Fitri, Y. (2014). Analisis Pelaksanaan Promosi Jabatan pada PT. Telkom Prkanbaru. Jom FISIF, 22(1), 336-349. https://doi.org/10.1016/s1013-7025(09)70018-1

Hasibuan, M. (2013). Manajemen Sumber Daya Manusia. jakarta: PT. Bumi Aksara.

Kridharta, D., \& Rusdianti, E. (2017). Analisis Pengaruh Karakteristik Individu, Komitmen Organisasi, Dan Kepuasan Kerja Terhadap Kinerja Karyawan Dengan Motivasi Sebagai Variabel Intervening. Jurnal Riset Ekonomi Dan Bisnis, 10(3), 232. https://doi.org/10.26623/jreb.v10i3.882

Munadiah, M. I. (2015). Pengaruh promosi jabatan terhadap kinerja pegawai negeri sipil di kantor sekretariat daerah kabupaten luwu. 1, 251-264.

Puspasari, N. M. O., \& Satrya, I. G. B. H. (2019). Pengaruh Prestasi Kerja, Senioritas Dan Loyalitas Karyawan Terhadap Promosi Jabatan. E-Jurnal $\begin{array}{llll}\text { Manajemen Universitas } & \text { Udayana, } & \text { 8(12), }\end{array}$ https://doi.org/10.24843/ejmunud.2019.v08.i12.p24

Rahayu, S. (2017). Pengaruh Promosi Jabatan terhadap Kinerja Karyawan pada PT. Garuda Metalindo. Jurnal Kreatif, 5(1), 18-29. Retrieved from http://openjournal.unpam.ac.id/index.php/kreatif/article/viewFile/701/571

Ritonga, A. H., \& Lubis, A. A. (2015). Pengaruh Promosi Jabatan Terhadap Kinerja Karyawan Pada PT Herfinta Farm \& Plant Kantor Cabang Medan. Publikauma: Jurnal Administrasi Publik Universitas Medan Area, 3(2), 112125. 
Saputra, I., \& Sudharma, I. (2017). Pengaruh Promosi Jabatan, Pelatihan Dan Lingkungan Kerja Terhadap Kepuasan Kerja Karyawan. E-Jurnal Manajemen Universitas Udayana, 6(2), 1030-1054.

Sunaryo. (2016). pengaruh pendidikan dan penempatan kerja terhadap kinerja karyawan di PTPN III medan. Jurnal Ilmiah Manajemen Dan Bisnis, 17(april), 88-100.

Suryalena, A. D. S. (2017). pengaruh prestasi kerja dan loyalitas terhadap promosi jabatan PT. Agung Automall Pekanbaru Branch. JOM FISIF, 4(2), 1-14.

Sutrisno, E. (2010). Budaya Orgaisasi. jakarta: Prenada Media Grup.

Triasmoko, Denny., Moch, Djudi, M., \& Gunawan, Eko, N. (2014). Pengaruh Pelatihan Kerja Terhadap Kinerja Karyawan. Jurnal Administrasi Bisnis, Vol. 12(1), 10.

Wibowati, J. I. (2014). Pengaruh Kinerja Karyawan terhadap Promosi Jabatan Karyawan pada Koperasi Tiga Desa Bersatu Kec. Merapi Barat Kab.Lahat. 2. Retrieved from http://unpal.ac.id/userfiles/Jurnal-Januarida (Vo,2, No_6,April 2014).pdf 